\title{
CONE).(OES
}

CIÊNCIA E TECNOLOGIA

TECENDO SABERES DOCENTES: AS CONTRIBUIÇOOES DO PIBID NA VISAOO DE POS-GRADUANDOS EM CIÊNCIAS NATURAIS E MATEMÁTICA DO IFRN

\section{TECENDO SABERES DOCENTES: AS CONTRIBUIÇÕES DO PIBID NA VISÃO DE PÓS-GRADUANDOS EM CIÊNCIAS NATURAIS E MATEMÁTICA DO IFRN}

\author{
Dioginys Cesar Felix de Lima ${ }^{1}$, Xênia Silva Gomes Brandẽo ${ }^{2}$, Josivânia Marisa Dantas ${ }^{1}$ \\ ${ }^{1}$ Universidade Federal do Rio Grande do Norte - UFRN \\ ${ }^{2}$ Instituto Federal de Educação, Ciência e Tecnologia do Rio Grande do Norte - IFRN \\ <dioginyscesar@gmail.com>.<xenia.gomes@ifrn.edu.br>.<josivaniamd@yahoo.com.br>
}

DOI: $10.21439 /$ conexoes.v15i0.2095

\begin{abstract}
Resumo. O PIBID promove a inserção de licenciandos em formação nas escolas da educação básica, mantendo contato com a prática docente e gerando um conhecimento imensurável, que não é aprendido apenas na teoria, mas, sim, a partir da prática e das relações sociais estabelecidas no ambiente escolar. Este estudo pretende identificar as contribuições do PIBID no olhar de discentes do curso de Especialização em Ensino de Ciências Naturais e Matemática do IFRN, campus Parnamirim-RN. A pesquisa é de abordagem qualitativa, do tipo exploratória. Participaram do estudo 19 egressos do programa que eram discentes no curso de Especialização dos períodos 2018.2, 2019.1 e 2019.2. O instrumento de pesquisa utilizado foi um questionário, aplicado via Google Forms e divulgado nas redes sociais. O questionário continha 10 perguntas, sendo que em 9 delas utilizamos a escala de Likert. Os resultados indicam que o programa contribuiu para a construção da identidade docente durante a formação inicial dos pósgraduandos. O PIBID também proporcionou o contato, conhecimento profissional sobre diferentes metodologias, a importância do planejamento e reflexão crítica sobre a ação docente. As atividades desenvolvidas pelos licenciandos durante sua atuação no PIBID promoveram um aprendizado significativo no que diz respeito aos saberes docentes, principalmente os experienciais, que constituem a cultura docente em ação. Dados desta pesquisa apontam à necessidade de investigar e de registrar tais contribuições a partir da narrativa de egressos que estão atuando no mercado de trabalho em outros contextos, fortalecendo, assim, o programa e a sua permanência enquanto Política Nacional de Formação de Professores.
\end{abstract}

Palavras-chaves: Formação docente. Experiência formativa. PIBID.

\section{WEAVING TEACHING KNOWLEDGE: PIBID'S CONTRIBUTIONS IN THE VIEW OF GRADUATES IN NATURAL SCIENCES AND IFRN MATHEMATICS}

\begin{abstract}
PIBID promotes the inclusion of graduates in training in basic education schools, maintaining contact with teaching practice and generating immeasurable knowledge, which not only learned theory, but also from practice and established social relations in the school environment. This study aims to identify the contributions of PIBID not by students of the Specialization course in Natural Sciences and Mathematics at IFRN, campus Parnamirim-RN. Research and qualitative approach, exploratory type. 19 graduates of the program who were students of the Specialization course in two periods 2018.2, 2019.1 and 2019.2 participated in the study. Or research instrument used in the form of a questionnaire, applied via Google Forms and disseminated on social networks. The questionnaire contains 10 questions, knowing that in 9 of them we use the Likert scale. The results indicate that the program contributed to the construction of the teaching identity during the initial training of two graduate students. PIBID also provided or contacted professional knowledge about different methodologies, about the importance of planning and critical reflection on teaching action. The activities carried out by the graduates during their work do not promote significant learning at PIBID, not that they say they respect teaching knowledge, especially experiences, which constitute the teaching culture in action. Given this research, it is necessary to investigate and register these contributions from the narrative of advances that are affecting the labor market in other contexts, also strengthening the program and its permanence in the National Policy for Teacher Training.
\end{abstract}

Keywords: Teacher training. Formative experience. PIBID. 


\section{INTRODUÇÃO}

A trajetória acadêmica para os licenciandos é marcada por alguns desafios que devem ser superados pelos profissionais ao longo de toda a sua formação. Um desses desafios está relacionado com o distanciamento entre a teoria e a prática. Muitas vezes, o estímulo e o contato prático de cursar componentes curriculares durante a graduação e o estágio supervisionado não oportunizam e/ou são insuficientes na consolidação de aptidões práticas dos saberes docentes necessários que possam contribuir com a futura carreira. Para tanto, é essencial que os licenciandos tenham variadas experiências formativas no decorrer da graduação, com o intuito de fomentar sua atividade prática, bem como de auxiliar a construção da sua identidade profissional durante esse percurso.

Nessa direção, a formação de professores tem adquirido espaço nas reformas educacionais nos últimos anos. Gradativamente, o cenário e o debate na sociedade sobre políticas de formação e de valorização da profissão docente vêm acontecendo. E uma dessas iniciativas que incentivam outras atividades formativas foi criada a partir de políticas educacionais, como, por exemplo, o Programa Institucional de Bolsa de Iniciação à Docência (PIBID), que tem como um de seus objetivos gerais incentivar a formação de docentes em nível superior para a educação básica e contribuir para a valorização do magistério (BRASIL, 2010 1

Nesses 14 anos de existência do PIBID, milhares de licenciandos de todo Brasil puderam participar desse programa. As atividades do programa se diversificaram, mas há muito ainda para saber sobre as contribuições que ele pode oferecer na formação docente. Entre as contribuições relatadas na literatura Ambrosetti et al. (2013), descrevem que o programa favoreceu o encontro da Universidade e o conhecimento da realidade escolar, bem como conhecimentos pedagógicos que subsidiaram a formação inicial. Já o estudo de Lima et al. (2019) aponta que o PIBID proporcionou aos licenciandos um contato antecipado com a rotina da docência - o que levou à adoção de hábitos essenciais para um profissional do magistério, como manter boas relações com os alunos, construção do planejamento, postura, desenvolver pesquisas, entre outros.

Sabemos que o PIBID promove a presença dos pro-

${ }^{1}$ [O PIBID foi criado em 2007. É um programa do governo federal que foi regulamentado pelo Decreto $\mathrm{n}^{\circ} 7.219$, de 24 de junho de 2010. Ele está vinculado à Diretoria de Educação Básica Presencial (DEB) da Coordenação de Aperfeiçoamento de Pessoal de Nível Superior (CAPES), em que se encontram as informações gerais do programa. Para maiores detalhes a respeito do PIBID, acessar o site: https://www.gov.br/capes/pt-br/acesso-a-informacao/acoes-eprogramas/educacao-basica/pibid.] fessores em formação na educação básica em várias ocasiões e em momentos importantes da rotina escolar. Dentre esses, destacamos a regência em sala de aula, reuniões de pais e professores, feiras científicas e diversas atividades. Conforme Martins, Farias e Cavalcante (2012), esse contato direto e constante com a escola, ainda no momento da formação inicial, gera um conhecimento imensurável, que não é aprendido apenas na teoria, mas, sim, a partir das relações sociais estabelecidas no ambiente escolar, possibilitando habilidades e competências na formação docente, saberes únicos que podem ajudar a prática docente no futuro.

Nessa perspectiva, observamos que alguns estudos foram desenvolvidos a partir de investigações de como o PIBID pode contribuir com a formação de professores na construção de saberes da docência e da identidade docente. Em sua maioria, essas pesquisas se detêm no olhar de graduandos e de supervisores, mas poucas delas se referem aos egressos e à sua atuação no mercado de trabalho.

Em consonância com nossa hipótese de pesquisa, trazemos os estudos de Oliveira (2014), Demari (2017), que versam sobre as contribuições do PIBID na visão de egressos de cursos de licenciatura. Esses estudos possuem reflexões convergentes, ambos evidenciam que o programa é uma ferramenta propulsora, motivadora na escolha da profissão docente e antecipa uma familiaridade com o ambiente escolar. Ressaltam, ainda, que a participação do licenciando no PIBID representa uma oportunidade de partilhar as aprendizagens individuais e coletivas entre os colegas. Desse modo, podemos considerar, aqui, o PIBID como mais um espaço formativo que vem contribuindo para a capacitação docente em sua formação inicial. O fato "inovador" proposto em nosso estudo foi o de compreender como essa experiência formativa contribuiu para a construção da identidade docente de professores que fizeram parte do curso de Especialização de Ensino de Ciências Naturais e Matemática do Instituto Federal do Rio Grande do Norte (IFRN), campus Parnamirim-RN, matriculados nos períodos de 2018.2, 2019.1 e 2019.2.

A investigação desenvolvida partiu do interesse decorrente da experiência do pesquisador, que atuou no PIBID ao longo de 2015 a 2017, no Subprojeto Interdisciplinar do Centro de Educação e Saúde (CES) da Universidade Federal de Campina Grande (UFCG), campus Cuité-PB. Essa participação trouxe algumas reflexões a respeito da educação, sobre a escola, sobre a vida, sobre ensinar e aprender, além de diversas vivências em diferentes contextos educacionais.

Segundo Pimenta e Lima (2012), a identidade do professor é construída ao longo de sua trajetória como 
profissional do magistério na formação inicial. Ela compreende que esse é um espaço em que são iniciadas as opções e as intenções da profissão que o curso pretende validar. Sabendo que os professores são os principais mediadores dos saberes docentes e escolares, para Tardif (2014), "Interessar-se pelos saberes e pela subjetividade deles é tentar penetrar no próprio cerne do processo concreto de escolarização". Sob esse viés, o PIBID se configura como uma dessas vivências que ajudam na formação, e, nesse estudo foi possível investigar como essa colaboração pode acontecer.

Este estudo teve como principal objetivo identificar as contribuições do PIBID que auxiliaram a construção da identidade docente, no olhar de discentes da Especialização de Ensino de Ciências Naturais e Matemática do IFRN, campus Parnamirim-RN. Para tal, foi necessário investigar que atividades trabalhadas estimularam a seguir à docência e discutir as suas contribuições.

O desenvolvimento do estudo é apresentado em quatro momentos. Na primeira sessão, caracterizamos o PIBID enquanto Programa Institucional e descrevemos os tipos de saberes docentes. Na segunda sessão, apresentamos algumas experiências de licenciados que atuaram no âmbito do PIBID, e, na terceira, o percurso metodológico. Por fim, discutimos os dados da pesquisa a partir das narrativas dos participantes dela.

\section{O PIBID EM ARTICULAÇÃO COM OS SABE- RES DOCENTES}

O PIBID consiste em um Programa institucional, conduzido por um coordenador institucional, apoiado por uma equipe de coordenadores de gestão, equipes de subprojetos com um coordenador de área (professor de ensino superior), dois supervisores nas escolas (professores da educação básica) e bolsistas de iniciação à docência (ID) (estudantes de licenciatura). As atividades desenvolvidas pelas equipes de subprojetos consistem em planejar, executar e avaliar atividades de ensino na educação básica.

Segundo o decreto $\mathrm{n}^{\mathrm{o}} 7.219$, de 24 de junho de 2010 , alguns de seus objetivos são: o incentivo a formação docente em nível superior para a educação básica, valorização do magistério, contribuir com a articulação teoria e prática, incentivo a prática de metodologias inovadoras interdisciplinares (BRASIL, 2010).

O Programa abre espaço para desenvolver atividades de uma forma não linear, de uma forma não opressora, onde a relação entre estudantes e professores se dá de forma horizontal. As atividades são desenvolvidas a partir do pensar da educação libertadora e problematizadora, valorizando as práxis e o diálogo, a fim de conscientizar os estudantes do mundo em que o cercam, para que eles possam intervir em sua realidade e possa transformá-la (FREIRE, 1981).

Segundo a Lei de Diretrizes e Bases da Educação Nacional (LDB), em seu artigo $1^{\circ}$ :

A educação abrange os processos formativos que se desenvolvem na vida familiar, na convivência humana, no trabalho, nas instituições de ensino e pesquisa, nos movimentos sociais e organizações da sociedade civil e nas manifestações culturais (BRASIL 1996 p. 01).

Se a educação é algo amplo, a formação dos professores não deve ficar restrita às quatro paredes da sala de aula, pois, para formar cidadãos críticos e atuantes, deve haver um diálogo entre todas as áreas, entre a Universidade, a escola e a sociedade; e o PIBID é um espaço que contribui para a formação de professores.

Contudo, essa formação não é apenas técnica, ela também é humana, ao se compreender a importância desse profissional no cotidiano escolar e na busca da humanização dos estudantes. O PIBID possui os elementos necessários para tal formação, pois envolve professores em formação, professores universitários e professores da educação básica, criando condições para uma formação inicial consistente, articulada, com possibilidades de se tornar, de verdade, um fruto da relação universidade-escola (BARBOSA, 2014).

É durante a formação docente que se ratificam elementos para a construção da identidade profissional do professor. Pimenta (1996) descreve que essa construção se dá a partir da significação social da profissão, da revisão das tradições, a partir de seus valores, conceitos, de seu modo de situar-se no mundo, de suas representações e saberes, em constante mudança, pois ela não é um dado imutável. Vale ressaltar que a identidade docente não se constitui somente no período da formação inicial, mas durante toda a trajetória escolar do estudante, que foi dando novo significado ao ser professor, transformando-se constantemente a cada nova experiência.

Nesse novo contexto contemporâneo, as identidades não são fixas nas pessoas, elas estão em constante transformação e processo. Por isso, devemos pensá-la a partir do seguinte conceito:

A identidade não está ligada a ser, mas a estar, ou mais especificamente, a representar. Sendo a identidade uma construção social, e não um dado, herdado biologicamente, ela se dá no âmbito da representação: a identidade representa a forma como os indivíduos se enxergam uns aos outros no mundo (TILIO, 2009, p. 112, grifo nosso). 
A formação docente não se constrói por acumulações de conhecimentos, entre cursos de formação, mas, sim, a partir de um processo constante de reflexão crítica sobre as suas próprias práticas, que podem reconstruir sua identidade profissional (NÓVOA, 1992). O professor deve ter uma reflexão crítica sobre sua prática educativa. Para Paulo Freire (1996, p. 24), “A reflexão crítica sobre a prática se torna uma exigência da relação teoria/prática sem a qual a teoria pode ir virando bláblá-blá e a prática, ativismo". Só a partir dessa reflexão crítica é que os sujeitos docentes vão se moldando, se transformando.

É através da própria experiência de vivenciar o programa PIBID que a identidade profissional docente vai se moldando, se construindo a partir da prática no chão das escolas. Esse contato com a escola possibilita o licenciando a começar a estabelecer a relação de vínculo com o ato de ensinar, a refletir sobre as instituições de ensino, sobre sua prática, sobre ser professor. Assim, consideramos que o PIBID se constitui como mais um local de autoformação, pois, a partir dessas vivências podem surgir as práxis sobre os saberes da docência, que, para Pimenta (1996, p. 11), "É nesse confronto e num processo coletivo de troca de experiências e práticas que os professores vão constituindo seus saberes".

Esse saber é definido por Tardif (2014, p. 255) no sentido amplo, "que engloba os conhecimentos, as competências, as habilidades (ou aptidões) e as atitudes, isto é, aquilo que muitas vezes foi chamado de saber, saberfazer e saber-ser". Para o autor, o saber docente é um saber plural. Ou seja, é construído por diversos fatores, como, por exemplo, o profissional, que se refere aos saberes que são mediados pelas instituições formadoras de professores, aos saberes disciplinares que correspondem ao diverso campo do conhecimento e emergem da tradição cultural, aos saberes curriculares que se referem aos programas escolares e aos saberes experienciais - este último se refere aos saberes práticos que surgem a partir do trabalho cotidiano.

Nessa perspectiva, hoje há professores que participaram do Programa PIBID, construíram sua identidade docente a partir das experiências ao cursarem os componentes curriculares de seus cursos. Assim, espera-se que eles tenham adquirido algumas competências referentes aos saberes da docência durante as práticas vivenciadas no PIBID.

Pesquisar a identidade docente partindo de um contexto de um grupo de professores que atuou junto ao PIBID é também estar atento aos múltiplos contextos que compõem a construção desse processo, que está em constante movimento.

\section{A FORMAÇÃO DOCENTE E EXPERIÊNCIAS DO PIBID}

A formação dos professores consiste em um processo de vivências, de experiências e de desafios enfrentados durante a formação inicial, e, posteriormente, durante à prática profissional por meio da formação continuada. Para Tardif (2014), há uma grande defasagem da Universidade quanto à formação docente. $\mathrm{O}$ autor ressalta que o currículo das instituições de ensino superior valoriza o conhecimento teórico distanciado da situação prática da escola, formando profissionais carentes da associação entre o saber (teoria) e o saber fazer (prática).

Nessa direção, experiências formativas são muito importantes durante a graduação. O Estágio Curricular Supervisionado foi o espaço criado para estabelecer essa relação na formação inicial de professores, oportunizando, assim, o saber fazer, mas ele sempre enfrentou inúmeras dificuldades para cumprir sua função. A participação em projetos de pesquisa e extensão, como o PIBID, concebe a escola como espaço necessário à formação do profissional docente, mas parece haver elementos que distinguem tais atividades e apontam maior eficiência do PIBID nessa relação (LEITE, 2016).

O estudo de Obara, Broietti e Passos (2017), realizado com estudantes de Química que participaram do PIBID, revela algumas evidências relacionadas à motivação e à mobilização; à prática e à reflexão sobre a ação; à pesquisa no ensino de Química e à construção de um perfil docente - que carrega em si as dimensões epistêmicas, pessoais e sociais da relação com o saber. Além disso, foi percebido que o PIBID cumpre o papel de motivador do interesse pela profissão docente, sendo um campo frutífero para a idealização de uma identidade docente.

Outros elementos que parecem distinguir maior eficiência ao Programa foram relatados no estudo de Silva, Sobrinho e Costa (2018) a partir do depoimento de licenciandos em Ciências Biológicas. Para eles, o PIBID oportunizou novas técnicas, como estas, por exemplo: a verdadeira percepção das dificuldades da sala de aula, por passarem mais tempo nas escolas; o ganho de autonomia em sala; e o rompimento de medos e de inseguranças vivenciadas antes de cursar o estágio supervisionado.

Segundo Corrêa et al. (2012), licenciandos, sem ou com pouca experiência em sala de aula, a partir da passagem pelo programa, sentem-se, a princípio, receosos, como também desafiados pelos próprios erros, pois eles estão sendo avaliados todo o tempo pelos professores supervisores e pelo coordenador de área - o que, de certa forma, oportuniza reavaliações de postura, de 
adaptações, seguidas de críticas construtivas, que levam à constituição de características distintas dos padrões rotineiros, nos quais podem se formar professores na prática.

Além disso, nos estudos de Santos et al. (2018), desenvolvidos com licenciandos em Física, verificou-se que o PIBID, apesar das suas limitações, proporcionou um contato com metodologias diferenciadas de ensino disponíveis ao professor de Física que ultrapassaram o uso limitado de experimentos, além da superação por parte dos licenciandos - ao que se refere à timidez. Para eles, as vivências práticas estimulam ser um professor pesquisador e incentivam a continuar a formação acadêmica.

Os resultados de Dantas, Santos e Cunha (2014) apontaram que o PIBID favorece à criação de um espaço de construção de um novo conhecimento, produzido nas relações entre instituições e sujeitos, integrando os diferentes saberes que constituem o conhecimento profissional. A partir dos depoimentos dos licenciandos, foi ressaltado que os problemas enfrentados na escola resultaram em ações inovadoras, ocasionando um diálogo entre a realidade escolar e a academia.

Por outra perspectiva, o PIBID também auxilia no incentivo a publicações de artigos e resumos, como demonstra o estudo de Rodrigues et al. (2016), que relata uma investigação das contribuições do PIBID subprojeto Matemática no Brasil. Nesse incentivo, há trocas do saber fazer a partir de congressos, de encontros e de seminários. Além disso, a partir dos depoimentos dos participantes, foi percebido o estímulo para que se tornem futuros professores-pesquisadores de suas práticas pedagógicas.

Podemos considerar que o PIBID constitui uma importante alternativa para o fortalecimento das licenciaturas. Não se pode negar que a bolsa ofertada pelo governo pode ser um grande estímulo à participação no programa. No entanto, concordamos com Leite (2016), ao mencionar que essa experiência pode contribuir significativamente na formação dos futuros professores, no processo de ensino e aprendizagem, tornando-os mais experientes e familiarizados com o ambiente escolar.

\section{PERCURSO METODOLÓGICO}

Nosso estudo é de abordagem qualitativa, que utiliza os sentidos como forma de obter a informação sobre determinados aspectos da realidade, tendo o ambiente natural como fonte direta de dados e o pesquisador como seu principal instrumento (LUDKE; ANDRé, 1986).

Trata-se de uma pesquisa exploratória. Gil (2008), versa que essas pesquisas são desenvolvidas com o objetivo de proporcionar uma visão e aproximação acerca de um determinado fato. Ela ainda tem a finalidade de esclarecer, de desenvolver, de modificar conceitos e ideias - tendo em vista a formulação de problemas mais precisos e de hipóteses pesquisáveis para estudos posteriores.

Participaram do estudo egressos do PIBID matriculados no curso de Especialização de Ensino de Ciências Naturais e Matemática do IFRN, campus ParnamirimRN dos períodos de 2018.2, 2019.1 e 2019.2, formados em Ciências Biológicas, Química, Física e Matemática.

$\mathrm{O}$ instrumento de pesquisa utilizado foi um questionário, compreendido por (MARCONI; MARIA., 2003. p. 201) como "Um instrumento de coleta de dados, constituído por uma série ordenada de perguntas, que devem ser respondidas por escrito e sem a presença do entrevistador". Ele foi aplicado com o auxílio da internet pelo Google Forms e divulgado com o uso das redes sociais.

O questionário continha dez perguntas, sendo que em nove delas utilizamos a escala de Likert. Escolhemos tal escala por apresentar as seguintes vantagens: facilidade de o pesquisador construir e compilar melhor os dados (LAVILLE; DIONNE, 1999, MCCLELLAND, 1976) e alta adesão ao meio digital (FRANKENTHAL, 2017). Junto a essas nove questões, o questionário continha uma pergunta aberta, que teve o intuito de nos aproximarmos da subjetividade dos indivíduos pesquisados. Após a coleta de dados, realizamos as análises para a redação das discussões.

\section{NARRATIVA DE EGRESSOS E DISCUS- SÕES}

Nesta pesquisa, participaram 19 professores. 7 deles eram licenciados em Ciências Biológicas; 5, em Química; 1, em Física; e 6, em Matemática. Quanto a estar atuando na profissão, 52,6\% (10 participantes) deles apontaram não estar atuando em sala de aula, e 47,4\% (9 participantes) afirmaram estar atuando. Ao serem questionados há quanto tempo exerciam a profissão, observamos que eles possuíam de 7 meses a 6 anos de carreira docente.

Todo o universo pesquisado buscou se qualificar para o mercado de trabalho a partir do curso de especialização, reconhecendo a relevância dele para a sua formação acadêmica e carreira profissional. Nesse sentindo, podemos dizer que a passagem pelo curso de especialização possibilitou o ganho de aptidões teóricas ao que se refere aos saberes profissionais e disciplinares (TARDIF, 2014).

Nos depoimentos dos pesquisados, foi se evidenciando um percurso de construção e de reconstrução de conhecimentos, de conceitos, de valores, de concepções 
e de crenças sobre a escola, os alunos e a profissão docente. $\mathrm{Na}$ análise a seguir, são discutidos alguns aspectos que se destacaram nos dados.

Ao serem questionados como o PIBID repercutiu em sua prática docente, alguns dos participantes mencionaram que o programa se diferenciou ou, de certa forma, os preparou para o estágio - oportunizando outras aprendizagens, conforme poderemos observar nos próprios depoimentos:

\footnotetext{
"Ao participar do PIBID pude vivenciar e experimentar a docência diferenciada do estágio, mantendo um contato mais direto com a escola. Essa experiência fez a diferença na minha formação" (Professor A).

"O PIBID foi um grande aliado no meu crescimento acadêmico, pois o mesmo me preparou para o estágio; pude ter contato com a sala de aula bem antes do estágio e isso me ajudou bastante. Além disso, com o PIBID consegui aumentar minhas publicações científicas. O que de certa forma me ajudou bastante na seleção do meu mestrado e da especialização" (Professor B).

"Talvez o PIBD tenha sido o "estágio que deu certo"na minha licenciatura, sendo o momento em que eu realmente pude vivenciar o espaço escolar no papel e na perspectiva de professor (e não apenas minhas experiências da perspectiva de um aluno). Nessas vivências compreendi melhor os desafios da escola, os macetes, a relação profissional dos professores das várias disciplinas, a relação com a coordenação pedagógica e demais funcionários. Pude assim fortalecer minha escolha pela docência, minha identidade com a docência" (Professor C).

"O PIBID ajudou diretamente na minha identidade docente, uma vez que foi na escola onde coloquei em prática todas minhas habilidades. Desse modo, sou muito satisfeito em ter sido bolsista neste programa. Além disso, muitas das pesquisas que desenvolvo na área de ensino começaram com o incentivo dos coordenadores desse programa" (Professor D).
}

Conforme pudemos observar, o PIBID proporciona um contato mais direto e um avanço das aprendizagens, ao que se refere ao saber fazer (prático). Para Pimenta (1996), é durante a passagem na formação inicial que os conhecimentos e habilidades ajudam a construir o saber-fazer dos professores, em um processo contínuo de construção das suas identidades como docentes.

Conforme os depoimentos dos professores B e D, o programa também estimula e incentiva os docentes em formação a divulgar suas experiências com publicações de artigos e resumos, esse dado converge com os resultados do estudo de Rodrigues et al. (2016). Neste, foi observado que o programa estimula os participantes a se tornarem futuros professores pesquisadores de suas práticas pedagógicas.

O PIBID oportuniza aprender metodologias e instrumentos educacionais diferenciados, abordados a partir de temas geradores que levam à construção de projetos, sequências didáticas e/ou oficinas. A partir dos depoimentos a seguir, podemos verificar que essas vivências foram marcantes, tanto que elas ainda repercutem na prática daqueles que estão em sala de aula.
"[...] Pude vivenciar toda a teoria que eu via em sala de aula! O PIBID me estimulou a querer ainda mais viver a prática docente! Me mostrou estratégias que tenho cer- teza de que levarei pra minha vida docente" (Professor E).
“[...] Incentivou o uso de variadas metodologias e auxi- lia no desenvolvimento de ideias para aplicação de aulas, eventos, oficinas, entre outros, de maneira a diversificar o universo escolar de ensino e aprendizagem" (Professor F).
"Que o planejamento das aulas é mais eficaz para a prá- tica. Trabalho em equipe, que tudo dá certo com todos os membros da comunidade escolar trabalhando juntos. Dinamizar as aulas. Buscar fazer a minha parte na edu- cação da melhor maneira" (Professor G)
"A iniciação também foi palco de criatividade e plane- jamento de aulas diferenciadas, seja com experimentos, jogos, teatro, assim como incentivo a participação em eventos. Experiência fundamental para o ser professor que me tornei" (Professor H).

A passagem pelo PIBID estimulou tais professores a seguirem pelas veredas da docência. Foi a partir dessas vivências que surgiram os saberes experienciais destacados por Tardif (2014), como o conjunto de saberes atualizados, adquiridos e necessários da prática docente, que não provem das instituições de formação nem dos currículos. Tais saberes experienciais (saberes práticos), constituem, por assim dizer, a cultura docente em ação.

Nesses depoimentos, pudemos observar que os saberes experienciais foram fundamentais para os professores, uma vez que, a partir deles, vimos que as atividades diferenciadas ainda repercutem e estimulam os professores a diversificarem suas práticas com metodologias diferenciadas. Isso oportuniza diferentes tipos de aulas para além daquela tradicional, o que pode melhorar o ensino-aprendizagem dos estudantes.

Outros pontos que podemos destacar do contexto dos depoimentos são a compreensão dos professores pela necessidade do ato de planejar e a importância do trabalho em equipe. Essas percepções podem ter sido construídas durante a práxis ocorrida antes e depois de executar as ações do PIBID entre os próprios professores em formação, nas reuniões de planejamento entre os supervisores ou coordenadores de área.

Para Paulo Freire (1996, p. 39), ensinar exige reflexão crítica sobre a prática. Nessa formação permanente, "A prática docente crítica, implicante do pensar certo, envolve o movimento dinâmico, dialético, entre o fazer e o pensar sobre o fazer". E é no ato de planejar que a ação/reflexão se intensifica. Consequentemente, 
o ato de reflexão a partir das experiências nos leva a se reconstruir e a se moldar enquanto sujeitos professores, na busca de levar um ensino e aprendizagem de melhor qualidade (NÓVOA, 1992).

No depoimento do Professor I, a seguir, podemos compreender que ele, a partir do PIBID, obteve a percepção de que os estudantes possuem diversas identidades, que trazem consigo diversas crenças, saberes prévios, e que são sujeitos construtores de suas próprias histórias.

"Acredito que o PIBID me fez entender melhor os desafios enfrentados pelo professor em sala de aula e a lidar com as situações encontradas na escola. Além disso, eu pude enxergar melhor os discentes como pessoas dotadas de história e saberes, e que merecem ser vistos como humanos" (Professor I).

O PIBID também oportuniza a compreensão das dificuldades enfrentadas pela escola e pela profissão, e os professores em formação acabam vivenciando na prática os problemas que assolam as escolas públicas. Para Tardif (2014), no exercício cotidiano de sua função, os professores podem se deparar com situações que exigem improvisação e habilidades pessoais, bem como a capacidade de enfrentar situações mais ou menos transitórias e variáveis. A partir desse relato, podemos observar que o programa abre espaço para refletirmos também esses desafios.

A seguir, iremos apresentar um bloco de perguntas que buscou investigar quais foram as atividades e as competências trabalhadas que ajudaram a seguir à docência. Os resultados estão reunidos na (Tabela 1).

A primeira pergunta: a) Incentivou a opção para a carreira do magistério? quando somamos as variáveis 4 e 5 , referentes a concordo e a concordo totalmente, observamos que $94,7 \%$ dos participantes relataram que o PIBID incentivou a seguir a carreira docente. Esse resultado corrobora com um dos objetivos apresentados pelos documentos oficiais desse programa, que é incentivar o docente em formação a seguir a profissão (BRASIL, 2010).

Na pergunta dois, b) Promoveu organizar e dirigir situações de aprendizagem? 100\% dos participantes afirmaram que o PIBID traz essa contribuição. Na pergunta três, c) Estabeleceu laços com as teorias subjacentes às atividades de aprendizagens? a maioria respondeu concordar que o programa estabelece laços com as teorias.

As perguntas d) Utilizou metodologias e recursos didáticos diferenciados? е e) Promoveu ações que estimularam a inovação, a ética, a criatividade? tiveram o percentual de $100 \%$. Todos os participantes afirmaram que utilizaram e fizeram uso da inovação, da ética e da criatividade. Ainda ao que se refere aos aspectos das práticas desenvolvidas, podemos dizer que o PIBID consegue, de certa maneira, atingir um outro objetivo, a saber: a contribuição com a articulação teoria e prática, incentivo à prática de metodologias inovadoras interdisciplinares (BRASIL, 2010).

$\mathrm{Na}$ pergunta seis, f) Utilizou recursos tecnológicos? as proposições respondidas que se destacaram foram $47,4 \%$ para concordo e $31,6 \%$ para concordo totalmente. Aqui, podemos refletir que para a grande maioria dos professores em formação houve a oportunidade de trabalhar com recursos tecnológicos.

Na pergunta sete, g) Promoveu a participação de outras vivências extraclasse, como reuniões pedagógicas, reuniões com pais, feiras científicas? as variáveis concordo e concordo totalmente, quando somadas, equivalem a $77,9 \%$. Esse resultado evidência que no universo pesquisado houve, para a maioria, vivências extraclasses que são muito importantes no fazer docente.

Na pergunta oito, h) O PIBID se diferencia do estágio ou outros projetos de extensão? as variáveis de destaque foram aquelas em que $27,8 \%$ concordaram e $66,7 \%$ concordaram totalmente. Aqui, podemos observar que a maioria percebeu que o programa se diferencia do estágio e outros projetos. Esse fator pode ter se ocasionado, segundo Leite (2016), por haver alguns elementos que distinguem maior eficiência nas atividades desenvolvidas no PIBID, como, por exemplo, o contato mais direto na escola, a ação/reflexão a partir do planejamento, e o trabalho em equipe.

Na pergunta nove, i) Promoveu trabalho em equipe com outros professores elou coordenador pedagógico escolar? as variáveis de destaque foram as de $36,8 \%$ para concordo e as de $47,4 \%$ para concordaram totalmente. Esses dados indicam que o PIBID não se restringiu apenas ao professor supervisor e suas turmas, pois a maioria dos entrevistados, como vimos, respondeu que houve interação com outros professores e coordenador pedagógico escolar - o que pode ter sido muito significativo, no tocante às aprendizagens dos saberes docentes, principalmente os experienciais (TARDIF, 2014).

\section{CONSIDERAÇÕES FINAIS}

Os resultados desta pesquisa indicam que o Programa PIBID contribuiu para a construção da identidade docente durante a formação inicial dos pós-graduandos, dados esses que corroboram com o apontado por (OLIVEIRA; PECHLIYE, 2018, p. 153), quando descrevem que o PIBID "Oportuniza a prática reflexiva como mote 
Tabela 1: Contribuições do PIBID para estudantes da Especialização em diferentes aspectos a partir da escala Likert

\begin{tabular}{|c|c|c|c|c|}
\hline PERGUNTAS & 1 & 3 & 4 & 5 \\
\hline a) Incentivou a opção para a carreira do magistério? & & $5,3 \%$ & $36,8 \%$ & $57,9 \% *$ \\
\hline b) Promoveu organizar e dirigir situações de aprendizagem? & & & $50 \%$ & $50 \%$ \\
\hline $\begin{array}{l}\text { c) Estabeleceu laços com as teorias subjacentes às atividades } \\
\text { de aprendizagens? }\end{array}$ & & $5,3 \%$ & $63,2 \%$ & $31,6 \%$ \\
\hline d) Utilizou metodologias e recursos didáticos diferenciados? & & & $26,3 \%$ & $73,7 \%$ \\
\hline $\begin{array}{l}\text { e) Promoveu ações que estimularam a inovação, a ética, a } \\
\text { criatividade? }\end{array}$ & & & $63,2 \%$ & $36,8 \%$ \\
\hline f) Utilizou recursos tecnológicos? & $5,3 \%$ & $15,8 \%$ & $47,4 \%$ & $31,6 \%$ \\
\hline $\begin{array}{l}\text { g) Promoveu a participação de outras vivências extraclasse, } \\
\text { como reuniões pedagógicas, reuniões com pais, feiras } \\
\text { científicas etc.? }\end{array}$ & $10,5 \%$ & $10,5 \%$ & $42,1 \%$ & $36,8 \%$ \\
\hline $\begin{array}{l}\text { h) O PIBID se diferencia do estágio ou de outros projetos } \\
\text { de extensão? }\end{array}$ & $5,6 \%$ & & $27,8 \%$ & $66,7 \%$ \\
\hline $\begin{array}{l}\text { i) Promoveu trabalho em equipe com outros professores } \\
\text { e/ou coordenador pedagógico escolar? }\end{array}$ & & $15,8 \%$ & $36,8 \%$ & $47,4 \%$ \\
\hline
\end{tabular}

Fonte: Dados da pesquisa

Legenda: (1) discordo totalmente, (2) discordo, (3) indiferente (ou neutro), (4) concordo e (5) concordo totalmente. *As porcentagens apresentadas nesta tabela se referem a somatória (frequência absoluta) das variáveis respondidas por todos os pesquisados.

à melhoria da função docente, que auxilia na construção da identidade pessoal e profissional do docente".

Nesta investigação, também foi possível notar que houve diversidade de atividades trabalhadas, o que ajudou os professores em formação a seguir pela docência, devido a um maior engajamento dos alunos nas escolas e nos grupos de estudos na Universidade. Esse tipo de participação desperta o interesse pela pesquisa científica na área de ensino, e parece desencadear um maior interesse para o processo de reflexão sobre a prática docente. Esses resultados corroboram com outros estudos que estão relacionados à mesma temática, como o de Feitosa et al. (2020), Pereira, Pereira e Carvalho (2019), Obara, Broietti e Passos (2017), Rodrigues et al. (2016).

Podemos inferir que o PIBID se configura como um programa que tem um inegável potencial formativo e trabalho consistente, o que beneficia tanto os licenciandos das IES, quanto os professores da educação básica - conforme a narrativa dos professores pesquisados. A partir das reflexões das respostas desses docentes, é possível afirmar que o programa proporcionou experiências que são reproduzidas com bastante êxito nas escolas e, consequentemente, culminaram em um retorno social para a Educação Básica, cumprindo o seu papel enquanto política pública que potencializa a valorização da profissão docente.

A partir dos depoimentos, observamos que as atividades trabalhadas no PIBID promoveram um aprendizado significativo no que diz respeito aos saberes docentes, principalmente os experienciais, que constituem a cultura docente em ação.

Apesar do presente estudo apontar contribuições positivas, é necessário destacar que o PIBID, nos últimos anos, vem sofrendo ameaças de cortes de verbas, modificações e retrocessos. Tudo isso coloca sua permanência em risco. Tais problemas são decorrentes dos conflitos de interesses políticos para a pasta da Educação no Brasil e, consequentemente, para programas de formação de professores - problemas esses que deixam dúvidas sobre o seu fortalecimento e sobre a continuidade do programa no futuro.

Por fim, os dados desta pesquisa apontam a necessidade de investigar e de registrar tais contribuições, a partir da narrativa de egressos que estão atuando no mercado de trabalho, para que, assim, possamos visualizar os benefícios para a formação docente e para a sociedade. Esses direcionamentos são necessários, pois auxiliam na divulgação dos resultados obtidos, fortalecendo assim o programa e a sua permanência enquanto Política Nacional de Formação de Professores.

\section{REFERÊNCIAS}

AMBROSETTI, N. B.; ARRUDA, M. d. G. C. de; ALMEIDA, P. A.; CALIL, A. M. G. C.; PASSOS, L. F. et al. Contribuições do pibid para a formação inicial de professores. Educação em Perspectiva, v. 4, n. 1, 2013.

BARBOSA, M. V. O pibid e as culturas formativas no âmbito das licenciaturas. In: BARBOSA, M. V.; 
TECENDO SABERES DOCENTES: AS CONTRIBUIÇÕES DO PIBID NA VISÃO DE PÓS-GRADUANDOS EM CIÊNCIAS NATURAIS E MATEMÁTICA DO IFRN

DANTAS, F. B. A. (Ed.). Reflexões sobre a formação inicial de professores no PIBID. Campina: Mercado das Letras, 2014.

BRASIL. Lei de Diretrizes e Bases da Educação Nacional n. 9.394/96. Brasília: [s.n.], 1996. Disponível em: <http://www.planalto.gov.br/ccivil_03/leis/L9394. htm>.

PIBID - Programa Institucional de Bolsas de Iniciação à Docência. Brasília: [s.n.], 2010. Coordenação de Aperfeiçoamento de Pessoal de Nível Superior. Disponível em: <http: //www.capes.gov.br/educacao-basica/capespibid>

CORRÊA, C. V.; SILVA, V. da; ALBUQUERQUE, M. G. de; RIBEIRO, E. da S. Reflexões acerca das possibilidades de contribuição do pibid para a formação docente de graduandos do curso de licenciatura em matemática da universidade federal de rondônia. In: ANAIS DO CONGRESSO. $\mathbf{1}^{\circ}$ Encontro Nacional PIBID-Matemática. Santa Maria: UFSM, 2012.

DANTAS, D. L. S.; SANTOS, J. C. O.; CUNHA, M. M. d. S. Contribuições do projeto pibid-biologia na formação de professores em ciências biológicas no ces/ufcg. Revista de Ensino de Ciências e Matemática, Universidade Federal de Campina Grande, v. 10, n. 5, p. 85-99, 2014.

DEMARI, J. A formação docente no PIBID/Química da UFRGS na perspectiva dos egressos do Programa. Dissertação (Mestrado em Educação em Ciências) - Universidade Federal do Rio Grande do Sul, Porto Alegre, 2017. $61 \mathrm{f}$.

FEITOSA, R. A.; DIAS, A. M. I.; SOUSA, E.; FERREIRA, Y. B. Contribuições do pibid para a formação de licenciandos em biologia. Revista de Ensino de Ciências e Matemática, v. 11, n. 4, p. 113-128, 2020.

FRANKENTHAL, R. Entenda a escala Likert e como aplicá-la em sua pesquisa. 2017.

Disponível em: <https://mindminers.com/ entenda-o-que-e-escala-likert/>

FREIRE, P. Pedagogia do oprimido. 9. ed. Rio de Janeiro: Paz Terra, 1981.

Pedagogia da Autonomia: Saberes

Necessários à Prática Educativa. 1. ed. São Paulo: Paz e Terra, 1996.

GIL, A. C. Métodos e técnicas de pesquisa social. 6. ed. São Paulo: Atlas, 2008.
LAVILLE, C.; DIONNE, J. A construção do saber: manual de metodologia da pesquisa em Ciências humanas. 1. ed. Porto Alegre: Artmed, 1999.

LEITE, L. M. L. Contribuições do PIBID na formação de professores no CES/UFCG: uma reflexão a partir do subprojeto interdisciplinar. Dissertação (Graduação em Ciências Biológicas) Universidade Federal de Campina Grande, Cuité, 2016. $46 \mathrm{f}$.

LIMA, E. S.; RODRIGUES, J. d. O.; ROCHA, F. D. d. S.; PINTO, C. A. S. Benefícios do pibid na formação de estudantes do curso de licenciatura em educação física: Uma revisão bibliográfica. Conexões-Ciência e Tecnologia, v. 13, n. 1, p. 15-22, 2019.

LUDKE, M.; ANDRé, M. Pesquisa em educação: abordagens qualitativas. [S.1.], 1986.

MARCONI, M. d. A.; MARIA., L. E. Fundamentos de metodologia científica. 5. ed. São Paulo: Atlas, 2003.

MARTINS, M. M. M. d. C.; FARIAS, I. M. S. d.; CAVALCANTE, M. M. D. Nos caminhos entre o estágio supervisionado e o pibid: o que contam os licenciandos de biologia? In: XVI ENDIPE Encontro Nacional de Didática e Práticas de Ensino. Campinas: UNICAMP, 2012.

MCCLELLAND, J. A. Técnica de questionário para pesquisa. Revista Brasileira de Física, v. 1, n. 1, p. 93-101, 1976.

NÓVOA, A. Formação de professores e profissão docente. [S.1.], 1992.

OBARA, C. E.; BROIETTI, F. C. D.; PASSOS, M. M. Contribuições do pibid para a construção da identidade docente do professor de química. Ciência \& Educação (Bauru), SciELO Brasil, v. 23, n. 4, p. 979-994, 2017.

OLIVEIRA, L. G. S.; PECHLIYE, M. M. Programa institucional de bolsa de iniciação à docência (pibid): Influências e contribuições na formação de professores em artigos publicados entre 2011 e 2014. Revista de Ensino de Ciências e Matemática, v. 9, n. 4, p. 153-168, set. 2018.

OLIVEIRA, M. C. S. Sentidos do Programa Institucional de Bolsa de Iniciação à Docência (PIBID) na formação de professores: um estudo com egressos da Universidade Federal de São João DEL - REI. Dissertação (Mestrado em Processos Socioeducativos e Práticas Escolares) — Universidade 
Federal de São João Del - Rei, São João Del - Rei, 2014. $121 \mathrm{f}$.

PEREIRA, M.; PEREIRA, I. B.; CARVALHO, F. V. Importância do pibid na formação dos discentes do curso de licenciatura em ciências biológicas do instituto federal de são paulo-campus são roque (sp).

Revista de Ensino de Ciências e Matemática, v. 10, n. 6, p. 185-202, 2019.

PIMENTA, S. G. Formação de professores: saberes da docência e identidade do professor. Revista da Faculdade de Educação, v. 22, n. 2, p. 72-89, 1996.

PIMENTA, S. G.; LIMA, M. S. L. Estágio e Docência. 7. ed. São Paulo: Cortez, 2012.

RODRIGUES, M. U.; SILVA, L. D.; MISKULIN, R. G. S.; FERREIRA, N. C. Contribuições do pibid para as licenciaturas em matemática do brasil. Ensino \& Pesquisa, v. 14, n. 01, 2016.

SANTOS, B. M.; SOUZA, G. A. P.; PEREIRA, A. C.; PARADA, E. M. de S. Formação inicial de professores de física na ufac: as contribuições e limitações do pibid. South American Journal of Basic Education, Technical and Technological, v. 5, n. 2, 2018.

SILVA, M. C. S.; SOBRINHO, F. S. L.; COSTA, J. B. V. A contribuição do pibid para a formação docente: Uma visão dos bolsistas do curso de ciências biológicas da universidade estadual de alagoas-uneal. Diversitas Journal, v. 3, n. 3, p. 691-695, 2018.

TARDIF, M. Saberes Docentes e Formação

Profissional. 17. ed. Petrópolis: Vozes, 2014.

TILIO, R. C. Reflexões acerca do conceito de identidade. Revista Eletrônica do Instituto de Humanidades, v. 8, n. 29, p. 109-119, abr. 2009. 